Página inicial: 643 - Página final: 660

Tipo de artículo: de Revisión

\title{
La familia en el marco de la justicia transicional: retos y reconocimientos ${ }^{i}$.
}

The family within the frame of transitional justice: challenges and acknowledgements.

\author{
Recibido: enero 2016 Revisado: abril 2016 Aceptado: mayo 2016
}

Por: José Fernando Valencia Grajales ${ }^{1}$

Resumen.

Se presenta una revisión histórica-holística al concepto de Familia, sus cambios al cabo de la historia, por un lado; luego, compara la familia tradicional cristiana, su conflicto con el mundo moderno, su composición dentro de la modernidad para luego planear dicho concepto y concepción de cara al contexto de violencia política, social y armada que ha vivido Colombia, para cerrar con una reflexión en torno al cómo estas configuraciones afectan o no los abordajes y desarrollos de la posible aplicación de la justicia transicional en el contexto de un posible pos conflicto ante la firma del acuerdo de Paz entre la insurgencia de las FARC-EP y el gobierno de Colombia, posiblemente ante un proceso similar con la insurgencia del ELN.

\section{Palabras claves.}

Familia, posconflicto, conflicto armado.

\begin{abstract}
.
A historical-holistic review to the concept of family, their changes at the end of the history is presented, on the one hand. Then, the traditional Christian family, its conflict with the modern world, its composition within modernity are compared, then, to plan this concept and conception for the context of political, social and armed violence that Colombia, has experienced, to conclude with a reflection on how these configurations affect whether approaches and developments in the possible application of transitional justice in the context of a possible post conflict in light of the signing of the peace agreement among the of the FARC-EP insurgency and the Colombian Government, possibly in light of a similar process with the ELN insurgency.
\end{abstract}

Key words.

Family, Post Conflict, Armed Conflict.

\footnotetext{
1 Docente investigador FUNLAM fundación Luis Amigo, abogado Universidad de Antioquia, politólogo Universidad Nacional de Colombia sede Medellin, especialista en Cultura Política: pedagogía de los derechos humanos UNAULA Universidad Autónoma Latinoamericana, Magister en Estudios Urbano Regionales de la Universidad Nacional de Colombia sede Medellín, estudiante del doctorado en conocimiento y cultura en américa latina Ipecal (Instituto Pensamiento y Cultura en América Latina, A.C.) editor de la revista Kavilando. Medellin, Colombia. Contacto: perseo@kavilando.org
} 


\section{Introducción.}

Estudiar la familia dentro del contexto del marco de justicia transicional puede resultar descabellado si se piensa la justicia transicional como un resultado meramente jurídico, sin embargo, no se puede desconocer el impacto psicosocial, histórico, político, económico y cultural que enmarca la composición moderna de la familia y cómo esta se ha enfrentado a fragmentaciones de tipo cultural- histórico- social frente a la modernidad y los contextos de violencia que implica haber sobrevivido fenómenos políticos como el desplazamiento forzado, la desaparición forzada, el secuestro, las violaciones, los señalamientos, las torturas y la perdida de todo asunto material y principalmente perder a los tuyos, Valencia (2014), (2011); (2009) ; (Valencia Grajales \& Marín Galeano, 2008). Lo anterior ha tenido explicaciones en Colombia argumentadas en las consecuencias del paramilitarismo, el narcotráfico, la pobreza, la riqueza o por temas políticos asociados a la guerrilla o ideológicos al ser miembro de la izquierda (Valencia Grajales J. F., 2011a) (Valencia Grajales \& Marín Galeano, 2010). A hora bien, nos aproximamos a un hito histórico que nos acerca a esa paz soñada, lo que a su vez nos pone frente al espejo que nos exige preguntarnos ¿cómo se debe recomponer la familia política (estatal, la ciudad, la comunidad) y ¿cómo la familia de sangre o afecto? ¿Cómo hacer que la familia sea incluida dentro del acuerdo marco de la Mesa de conversaciones de la Habana? ¿Cómo hacer que el punto 5 de los acuerdos de la Habana referente a las Víctimas, tanga en cuenta a la familia en su concepción afectiva de forma integral al momento de ser resarcidas por el Gobierno de Colombia y las FARC-EP? ¿Cómo hacer efectivos los Derechos humanos de las familias víctimas? ¿Cómo entregarles la Verdad? (Mesa de conversaciones de la Habana, 2012).

Dar respuesta a los anteriores interrogantes exige inexorables recorridos temporales que evidencien no solo históricamente qué es una familia, sino qué es la justicia transicional y cómo aplicarla en un contexto social aun influenciado por las BACRIM (bandas criminales - paramilitares) que podrian entorpecer el proceso. La metodología para abarcar el presente trabajo se funda en la investigación histórica-exploratoria por medio de la recolección de fuentes primarias y secundarias tanto escritas como orales, siendo flexible y versátil (Malhotra, 2008) con el fin de encontrar elementos de juicio tantos teóricos como históricos que evidencien las posibles dificultades a las que se enfrentaran los miembros de la sociedad al momento de implementar los acuerdos o integrar a la familia (nuclear, extensa, disfuncional, adoptiva, de acogida, reconstruida, étnica, cultural, de hecho, mono y poliparental) (UNICEF, 2003).

\section{La familia en la historia: una explicación holistica}

La familia ha sido una creación humana y como toda génesis sea remontado a explicaciones naturales (Darwinianas), psicológicas en donde el pasado no da respuesta al cómo y por qué los seres humanos se juntan y reproducen de forma espontánea, porque el ser humano tiene pulsiones que no siempre pueden ser explicadas por la razón (Freud, Tótem y Tabú, 1980)(Freud, 2006) A hora bien desde la antropología autores como Morgan, Lewis Henry (1870) han definido esta por medio de la evolución unilineal, la consanguineidad y afinidad, rebatidas por autores como Geertz, Clifford and Hildred Geertz (1975) que criticaba los sistemas de parentesco, o desdibujan el parentesco por medio de estudios como los hechos por Needham (1971)poniendo en duda la existencia de sociedades primitivas según Kuper, (1988) o llegando incluso a poner en entredicho el parentesco según Trautmann, (1987). Igualmente, la familia se ha intentado explicar desde el punto de vista mitológico apelando 
a justificaciones biológicas fundados en la raza, los genes e ideológicas políticas alentadas por la patria, la nacionalidad o la religión (Bel Bravo, 2000). Adicionalmente podrimos encontrar respuestas desde los fenómenos culturales definidos en la tribu, la etnia y el pueblo. (Engels, 2006)

\section{La familia en la Antigua Roma.}

La familia en Roma no estará conformada por hombre, mujer e hijos: por el contrario, su esencia se fundará en el paterfamilias, y esta estará conformada por los hijos, los nietos, la esposa, las concubinas, los clientes, los esclavos y esclavas. Pero adicionalmente el paterfamilias siempre podía disponer de cualquiera de ellos, es decir, los podía vender, matar o hacer de ellos lo que quisiera, sin que dichas decisiones estuviesen filtradas por los sentimientos como la culpa o pecado, fundado en la liberalidad de las costumbres sexuales. Además de que la herencia quedaba al agnado, y no necesariamente a los hijos (Gaii, 1845) ; (Gayo, 1965), Sin embargo, y a pesar de la influencia romana por más de un milenio, las familias occidentales de hoy no se asemejan en gran cosa a la configuración de la familia romana antigua.

\section{La familia cristiana: una contradicción del modelo occidental.}

La familia luego del periodo romano fue altamente influenciada por los cristianos, que ante los eventos de la toma de Roma por Alarico I y finalmente la abdicación de Augustuló frente a Odoacro (Odovacar) en el 476 D.C. (Fernández, 2005)sumado a las explicaciones de la caída por San Agustín (2007) y la intervención directa de Justiniano y el papa (Walford, 1846), determinaron una nueva configuración de la familia fundada en una explicación míticareligiosa (Adán y Eva) y la existencia de un padre (Dios) que exige una familia nuclear; sin embargo dicha exigencia no resolvió las pulsiones Freud (1980) (2006)de los seres humanos o sus comportamientos anómalos ajenos a una nueva imposición de comportamiento social (Merton, 2003).

\section{La familia moderna; ente el modelo religioso y su liberación.}

Pero la configuración de la familia estuvo llena de altibajos definidos especialmente por los diferentes periodos de guerra existentes, en la antigüedad (Peloponeso, medicas, púnicas...) (Tucidides, 1996); (César, 1986) las cruzadas, Guerra de Sucesión Española (Sáiz Serrano, 2003), Guerra de los Siete Años, Guerras Napoleónicas (Clausewitz, 1984), Primera y segunda guerra mundial, Guerra Fría y la Guerra contra el terrorismo entre otras. Todas ellas han creado un mundo en falta, teniendo una gran cantidad de teorías que no sirve para comprender el mundo que nos rodea porque se fundan en verdades con base en objetos falsos Zemelman, (1998), (1996) Es decir, la guerra no es una respuesta validad para resolver los problemas de la humanidad considerando los efectos que deja en los huérfanos de padre, madre, hijos, tíos, abuelos, hermanos..., en diferentes épocas, con una mayor o menor intensidad, lejanas o cercanas, directas o indirectas, pero finalmente han afectado a la humanidad y a la configuración que de la familia han tenido.

A lo anterior se suma que la modernidad con sus constante cambios, conexiones Debray (1997), (1998) (2008)invasiones a la privacidad con fines de control (Foucault, 1980), 1998, 1999), auto exposiciones (Sibilia, 2008), panópticos (Bentham, 2005)y distopias indeseadas convertidas en realidad (Zamiatin, 2005) (Orwell, 1980) ha puesto en evidencia 
aquellos comportamientos ocultos por una gran cantidad de hechos sociales propios del oscurantismo cristiano y de las religiones monoteístas-autoritarias-totalitarias y homogéneas, y cómo estas han actuado sobre el hombre a manera de neurosis colectiva, con el fin de darle explicaciones psicológicas el ser humano del porqué el mundo es imperfecto, o que la búsqueda de lo ideal se deriva de la explicación que da la religión. Sin embargo dicha dicotomía entre la realidad, y la explicación mítica se ha desvanecido a causa de las opresiones morales y las liberaciones mediáticas pero controladas que generan un malestar en la cultura (Freud, 2006), que decantan en una nueva sociedad en la que los seres humanos se sienten atrapados. El hombre se encuentra en medio de una neurosis obsesiva que exige comportamientos sociales que rayan con lo patológico siendo la neurosis en el ser humano de carácter individual, y donde la religión como institución se torna en una neurosis obsesiva universal. En donde la renuncia individual y colectiva a las pulsiones dadas constitucionalmente, nacidas de sus necesidades sexuales y eliminadas por la religión de forma egoísta. Freud, (1980) (1997).

La familia será entendida a través de la historia como el núcleo esencial o la institución principal de la sociedad, porqué por medio de ella se trasmite la cultura, la economía, la disciplina, la religión, los mitos, las neurosis, los cambios, las metas, comportamientos y procesos de adaptación dentro de una sociedad. Es por ello que esta institución se convierte en un eje central de la estructura social (Merton, 2003). En razón de que por medio de ella las figuras paternas proyectan en sus hijos los anhelos, deseos, frustraciones, pulsiones, temores, traumas, presiones, jerarquizaciones, órdenes y valores que de otra forma no se transmitirian.

Es por ello, que la familia hoy no puede ser entendida como una simple sumatoria de elementos o características definidas en diccionarios, constituciones, biblias o manuales, por el contrario, su conformación y comprensión derivan de la complejidad del ser humano individual, colectivo y diverso. Es decir, no estamos ante una total incertidumbre respecto de la familia, si no frente a la interacción humana que se interrelaciona con el otro y qué a través de los siglos solo fue visionado por los griegos y romanos cómo el hombre que debía auto cuestionarse constantemente en pro del encuentro de sí mismo y al hacerlo se permitía participar en la sociedad política (Castoriadis, 2007). Es la búsqueda de sentido y sentires que dé cuenta de la realidad lo que permitirá reencontrar la familia histórica, es decir, se debe tener bajo sospecha todas esas explicaciones científicas que han dado de la institución familiar para poder tener certeza de llegar a encontrar algún día a una respuesta (Zemelman, 2005):

Que el punto de partida tenga que buscarse en un fortalecimiento de la capacidad para desconcentrarnos frente a la historia, de manera de estar en condiciones de verla por encima de las condiciones de índole teórica e ideológica dominantes. En verdad, la capacidad de ver está ausente en muchos científicos. (Zemelman, 1992, p.127).

En razón de lo anterior no puede ser posible que expliquemos a la familia desde una concepción cerrada de la historia, es decir, no es validad una respuesta fundada en la evolución, tipo darwiniana, nada más alejado de la realidad. Porque las familias no responden hoy a conformaciones históricas, religiosas o genéticas, sino que han correspondido a sentires, solidaridades, confrontaciones, amores y desamores, es decir, no es estática, es por el contrario dinámica y compleja, y responde a nuestra historia individual, confrontada y compartida por nuestros congéneres. 
Es por lo anterior, que para esta investigación se entenderá la familia como un conglomerado de personas que comparten sentires, solidaridades y confrontaciones frente al mundo, razón por la cual la misma puede estar conformada por uno o más individuos, que pueden estar atados o no, por lazos de sangre, políticos, económicos, culturales, sociales, psicológicos e históricos. Pero, los mismos pueden estar condicionados por el espacio-tiempo que les correspondió vivir. Las anteriores claridades nos permitirán realizar mejores preguntas (Freire \& Faundez, 2014) frente al cómo entender y enfrentar las familias los procesos de victimización, guerra, los procesos de paz, el posconflicto y la justicia transicional.

\section{Procesos de paz, posconflicto y justicia transicional.}

En razón de los vientos de cambio que se acercan a Colombia, y el trabajo realizado por la gran cantidad de colectivos sociales e incluso por la intervención del estado y de las diversas ONGs parece tenerse algunas claridades, dentro de las cuales se podrian encontrar los conceptos de víctima, desplazado, DIH (derecho Internacional Humanitario), DH (derechos Humanos) y conflicto, las cuales han venido siendo vertidas en normas como la Ley 1448 de 2011, Decreto Nacional 4800, 4155, 4633, 4634 y 4635 de 2011 y el 3011 de 2013, además de las sentencias de la Corte Constitucional de Colombia C-250, C-715 de 2012 y C-280, C-458, C-581, C-753 y C-912 de 2013. Sin embargo dichas claridades generan nuevas necesidades frente a la posibilidad de llegar a un acuerdo de paz. Tal vez el más complicado sea determinar qué es un acuerdo de paz, ¿es la eliminación del conflicto material? es decir el cese al fuego, ¿es la reconciliación nacional? (repensando que es lo que debemos reconciliar y por qué), ¿'es democratización de la sociedad? (lo que implica incluso repensar el modelo económico ya que este genera las injusticias propiciadoras del descontento social que al no ser eliminadas, la paz podría ser solo temporal), ¿es renunciar a discutir las inconformidades de la sociedad? o ¿es la simple aceptación de lo acordado en la mesa? Dichas preguntas sirven de abrebocas frente a los problemas que se correlacionan con la familia como víctima, como agente político o mediador de la sociedad.

Temas abordados dentro del tratado de paz de Guatemala: 1. Reconciliación nacional 2. Exhortación al cese de hostilidades 3. Democratización 4. Elecciones libres 5. Cese de la ayuda a las fuerzas irregulares o a los movimientos insurreccionales 6 . No uso del territorio para agredir a otros estados 7 . Negociaciones en materia de seguridad, verificación, control y limitación de armamento 8. Refugiados y desplazados 9. Cooperación, democracia y libertad para la paz y el desarrollo 10 Verificación y seguimiento internacional 11. Calendario de ejecución de compromiso (Universidad Rafael Landivar y MINUGUA, 1997).

\section{Justicia transicional}

La justicia transicional en Colombia ha sido una construcción teórica surgida desde los años 80s con las primeras conversaciones con los grupos insurgentes, durante el periodo presidencial de Belisario Betancourt, donde se lograron los siguientes: Acuerdos Humanitarios y de Cese al Fuego $(\mathrm{CaF})$ de la Uribe, Fuerzas Armadas Revolucionarias de Colombia FARC (marzo 1984), Acuerdos Humanitarios y de Cese al Fuego (CaF), Movimiento 19 de Abril M-19 y Ejército Popular de Liberación EPL (agosto 1984), Acuerdos Humanitarios y de Cese al Fuego (CaF), Movimiento Autodefensa Obrera ADO (agosto 1984), Acuerdos Humanitarios y de Cese al Fuego (CaF), sectores del ELN (diciembre 1985 y abril y julio de 1986), Acuerdo entre las FARC y la Comisión de Paz (marzo 1986) para prorrogar acuerdo de la Uribe. Luego durante el periodo de Virgilio Barco se lograron: el Acuerdo del Tolima, M-19 (enero 1989), Acuerdos para iniciar procesos de paz con el EPL, PRT y Quintín Lame 
(mayo-junio 1990) Pacto político, M-19 (noviembre 1989) Acuerdo político, M-19 (marzo 1990). Más adelante, durante el periodo de César Gaviria se implementaron: Cravo Norte, Coordinadora Guerrillera Simón Bolivar CGSB (mayo 1991) Agenda de Caracas (junio 1991) Acuerdo final, Partido Revolucionario de los Trabajadores PRT (Enero 1991); EPL (febrero 1991); Quintín Lame (mayo 1991) Acuerdo final, Comandos Ernesto Rojas (marzo 1992) Acuerdo final, CRS (Abril 1994) y Frente Garnica (junio 1994) Acuerdo de Coexistencia, Milicias de Medellin (mayo 1994) (García Durán, Sarmiento Santander, \& Caraballo Acuña, 2009).

En una etapa no muy fructífera el presidente Ernesto Samper logró: el Acuerdo Humanitario de Remolinos del Caguán, FARC (junio 1997) Pre-acuerdo del Palacio de Viana (Madrid), ELN (febrero 1998) y el Acuerdo final, Movimiento Independiente Revolucionario-Comandos Armados MIR-COAR (julio 1998), después encontrariamos el esfuerzo realizado por el presidente Andrés Pastrana, con: Acuerdo Humanitario, ELN (junio 2000), Acuerdo Humanitario, ELN (octubre 2000), Acuerdo de Intercambio Humanitario, FARC (junio 2001), Agenda Común, FARC (mayo 1999), "Acuerdo de Los Pozos", FARC (febrero 2001), Condiciones para establecer una zona de encuentro con el ELN (mayo 2001) Informe Comisión de Personalidades (septiembre 2001), Acuerdo de San Francisco de la Sombra, FARC (octubre 2001), Acuerdo por Colombia, ELN (noviembre 2001), Acuerdo de cronograma para el futuro del proceso de paz, FARC (enero 2002) y finalmente encontramos el periodo del presidente Uribe quien negocia o pacta con los paramilitares por medio del: Acuerdo de Santa Fé de Ralito, AUC (julio 2003), Acuerdo para involucrarse en las negociaciones con los paramilitares del Bloque Central Bolivar y Vencedores de Arauca (noviembre 2003), el cual terminó en la dejación de armas y la creación de la primera ley de justicia transicional como lo es la Ley 975 de 2005 ) (García Durán, et al, 2009).

La ley 975 de 2005 denominada Justicia y Paz reguló los procedimientos para la investigación, procesamiento, sanción y beneficios judiciales de aquellos que pertenecían a grupos armados organizados al margen de la ley, que adicionalmente hubiesen cometido hechos delictivos durante su pertenencia a esos grupos y que lógicamente se hubiesen desmovilizado y en estado de arrepentimiento quisieran contribuir a la reconciliación nacional. Sin embargo, dicha norma abría un bache que permitía la interpretación y aplicación de la ley de conformidad con las normas constitucionales y los tratados internacionales ratificados por Colombia y aplicar discrecionalmente algunas disposiciones internacionales. Es decir, la norma era abierta y permitía una interpretación no restrictiva. Sin embargo y luego de una revisión exhaustiva de la norma por parte de la Corte Constitucional dentro de la Sentencia C-771/11 donde está la avala por los siguientes motivos:

"La comunidad internacional ha reconocido esta realidad, admitiendo una forma especial de administración de justicia para estas situaciones de tránsito a la paz, a la que ha llamado 'justicia transicional' o 'justicia de transición', pero no ha cedido en su exigencia de que las violaciones a los derechos fundamentales sean investigadas, enjuiciadas y reparadas, y los autores de las mismas contribuyan a identificar la verdad de los delitos cometidos y reciban algún tipo de sanción. (...)

4.2.4. La anterior declaración pone de manifiesto la admisión de una nueva noción de Justicia en el contexto de la comunidad internacional, que atiende a la necesidad de alcanzar la efectividad del derecho a la paz en aquellas sociedades en situación de conflicto, pero que a la vez pretende responder, aun en estas circunstancias, al imperativo de enjuiciar y reparar las graves violaciones a los derechos humanos y del Derecho Internacional Humanitario y lograr el esclarecimiento de la verdad al respecto, nueva noción de Justicia que opera dentro del tránsito de un período de 
violencia a otro de consolidación de la paz y de vigencia del Estado de Derecho, o de autoritarismo a otro de respeto al pluralismo democrático.

4.2.5. Así pues, la justicia transicional admite la existencia de una tensión entre el objetivo social de lograr un tránsito efectivo hacia la paz o la democracia, y los derechos de las víctimas a que las violaciones de derechos sean investigadas, enjuiciadas y castigadas por el Estado, y a que se logre una efectiva reparación. Para la resolución de esta tensión, el Derecho Internacional, partiendo de la base de que los compromisos de los Estados en el respeto de los Derechos Humanos no se suspenden ni interrumpen por las circunstancias de transición, formula ciertos lineamientos a fin de asegurar estándares mínimos en materia de justicia, verdad y reparación." (C.C. Sentencia C-771/11)

Sin embargo, dicha interpretación, no dejó a todos los magistrados tranquilos, y especialmente, porque algunos magistrados consideraron que dichos beneficios que entregaba dicha norma excedía los fines de la misma, porque se permitía que los delitos de lesa humanidad y otros referentes a como extender los beneficios de la ley a quienes hayan incurrido en el delito de concierto para delinquir agravado, constituye una desproporcionada afectación del valor de justicia y los derechos de las víctimas, además de incurrir en el desconocimiento de las obligaciones del Estado de perseguir, juzgar y sancionar las graves vulneraciones de los derechos humanos elementos que fueron expuestos por el Salvamento de Voto del Magistrado del magistrado Jorge Iván Palacio Palacio dentro de la Sentencia C-771/11, en ese mismo sentido se pronunció el magistrado Nilson Pinilla Pinilla quien lo hace en estos términos.

"En nuestra opinión, las normas cuestionadas no aseguran estándares mínimos en materia de justicia, verdad y reparación frente a las conductas delictivas de los desmovilizados de los grupos armados organizados al margen de la ley, en los términos del artículo $1^{\circ}$ de la Ley 975 de 2005" (C.C. Sentencia C-771/11) (...) En nuestra opinión, tal como está concebida y estructurada la Ley 1424 de 2010, conduce a que los objetivos de verdad, justicia y reparación que se insertan en el enunciado de la ley y en algunas de sus disposiciones, se conviertan en simple retórica, toda vez que las posibilidades reales de verdad judicial y por ende de justicia y reparación, se ven dramáticamente menoscabadas por la disposición del inciso segundo del artículo cuarto que prohíbe de manera absoluta el uso probatorio de cualquier información que surja en el marco de los acuerdos de contribución a la verdad y a la memoria histórica. (C.C. Sentencia C-771/11)

Es decir, que dicha norma contiene una serie de elementos contrarios a la búsqueda de la justicia, verdad y reparación, y esto se aprecia justamente en el hecho de que los paramilitares jamás fueron juzgados por sus delitos de lesa humanidad a pesar de ser confesados o haber sido documentados e identificados por las comisiones de la verdad. A lo que se suma que según la Unidad Nacional de Fiscalias para la Justicia y la Paz, y conforme al Consolidado estadístico a julio 31 de 2015 solo se han proferido 33 sentencias de los 4.237 miembros de las AUC postulados, a pesar de que ya se sabe que hay 57.883 Hechos Confesados y 84.354 víctimas relacionadas en hechos confesados, haber más de 6.420 cuerpos exhumados y encontrar 5.025 fosas comunes halladas. A lo anterior se suma que más de 2.000 desmovilizados han regresado a delinquir como BACRIM, es decir, por el momento este proceso de paz con los paramilitares ha sido un total fracaso. Esto se puede evidenciar en la siguiente tabla realizada por la Fiscalía: 
Las anteriores estadísticas evidencian como la justicia transicional aún tiene falencias, principalmente del orden de la justicia, porque no se han condenado a sus respectivos autores, ni simbólica, ni materialmente, especialmente en lo referente a las profundas violaciones de los derechos humanos, y solo se ha hecho algún tipo de justicia desde el punto de vista del narcotráfico, y ello en razón a las extradiciones a los Estados Unidos, y extrañamente a los miembros que hubiesen podido incriminar directamente el gobierno del expresidente Uribe. En lo referente a la verdad, la misma se ha visto minimizada a las grandes matanzas que no podian ser ocultadas y que muchas de ellas se han recuperado por los grupos de investigación histórica, pero no por los investigadores de la fiscalía o delaciones de los paramilitares, y finalmente la reparación, se ha limitado al pedido de perdón, sin que ello sea suficiente para redimir las afectaciones económicas o la recuperación de los bienes de aquellos que fueron despojados y que hoy dichos bienes permanecen en cabeza de testaferros o personas naturales, compañias nacionales y extranjeras que dicen haber actuado de buena fe (E1 Tiempo, 2008); (Revista Semana, 2016).

\section{Los acuerdos de la mesa de conversación con las FARC-EP.}

Hasta el momento, se han propuesto una serie de temas dentro de la mesa de conversación, especialmente en lo referente a la politica de desarrollo agrario integral, que busca impulsar la integración de las regiones y el desarrollo social y económico equitativo del país, el acceso y uso de la tierra. Crear una politica frente a las tierras improductivas y de formalización de la propiedad. Abrir espacios territoriales para una frontera agrícola y protección de zonas de reserva, impulsar los programas de desarrollo con enfoque territorial, Infraestructura y adecuación de tierras. Se discutió sobre el desarrollo social, incluyendo la Salud, educación, vivienda y la erradicación de la pobreza. Se propuso la estimulación de la producción agropecuaria y a la economía solidaria y cooperativa. Además de la asistencia técnica, la creación de subsidios, crédito y generación de ingresos, por medio del mercadeo, además de exigir la formalización laboral rural y mejorar el sistema de seguridad alimentaria (Mesa de conversaciones de la Habana, 2012) (Mesa de conversaciones de la Habana, 2015).

También se propuso la temática de Participación política, para lograr el reconocimiento de los derechos y garantías para el ejercicio de la Oposición política en general y en particular para los nuevos movimientos que surjan luego de la firma del Acuerdo Final. Acceso a medios de comunicación, para que se den mecanismos democráticos de participación ciudadana, incluidos los de participación directa, en los diferentes niveles y diversos temas. La aplicación de medidas efectivas para promover mayor participación en la política tanto nacional, regional y local de todos los sectores, incluyendo la población más vulnerable, en igualdad de condiciones y con garantias de seguridad (Mesa de conversaciones de la Habana, 2012, 2015).

Otra de las temáticas trabajadas fue el fin del conflicto, y como implementarlo por medio de un proceso integral y simultáneo que aplique el cese al fuego y de hostilidades bilateral y definitivo, la dejación de las armas, la reincorporación de las FARC-EP a la vida civil tanto en lo económico, como lo social y lo político en donde el Gobierno Nacional coordinará la revisión de la situación de las personas privadas de la libertad, procesadas o condenadas, por pertenecer o colaborar con las FARC-EP, además de intensificar el combate contra las organizaciones criminales y sus redes de apoyo, incluyendo la lucha contra la corrupción y la impunidad, en particular contra cualquier organización responsable de homicidios y masacres o que atente contra defensores de derechos humanos, movimientos sociales o movimientos políticos, y contra el paramilitarismo (Mesa de conversaciones de la Habana, 2012); (Mesa de conversaciones de la Habana, 2015). 
Así mismo, se han discutido el tema de las drogas ilícitas, considerado oportuno presentar como solución un programas de sustitución de cultivos de uso ilícito, así como planes integrales de desarrollo con participación de las comunidades en el diseño, ejecución y evaluación de los programas de sustitución y recuperación ambiental de las áreas afectadas por dichos cultivos, también programas de prevención del consumo y salud pública y estudiar una solución del fenómeno de producción y comercialización de narcóticos.

Otro de los puntos que se han abordado es el de las Víctimas, y el mecanismo para resarcirlas, por medio de la aplicación de los derechos humanos de las víctimas y la necesidad de brindar la Verdad. A ello se suma finalmente la implementación de mecanismos de verificación y refrendación del Acuerdo Final utilizando sistemas de implementación nacional y regional, creando comisiones de seguimiento y verificación e implementando mecanismos de resolución de diferencias. Adicionalmente contando con el acompañamiento internacional para los temas de cumplimiento del cronograma, presupuesto, difusión, comunicación y refrendación (Mesa de conversaciones de la Habana, 2012); (Mesa de conversaciones de la Habana, 2015).

\section{La familia y los acuerdos de paz.}

La familia a lo largo de los últimos 60 años en Colombia ha sufrido fuertes arremetidas en contra de cada uno de sus miembros, ello desde la violencia en Colombia cuando las madres, padres e hijos eran tomados a manera de ejemplo social, respecto del comportamiento exigible, conservador, liberal, chusma, pájaro (Pécaut,1987); (Pécaut, 2008); (Ortiz sarmiento, 1985); (Leal Buitrago, 2002); (Campo Chicangana, 2003); (Bergquist, 1981)en cada una de estas etapas el valor de la familia funciono a manera de retaliación, botín, y blanco. Ello con el fin de eliminar, destruir y debilitar al otro. Pero con la inevitable consecuencia de la pérdida de valores, identidades, cultura y transmisión de saberes y sentires.

Suponer a la familia como una víctima colectiva ayudaria a resolver muchos de los problemas psicoafectivos que se presentan al momento de la reparación y que, aunque no sean discutido de forma particular se ha ampliado el espectro a todos y todas, Mesa de conversaciones de la Habana (2012) (2015). La anterior apuesta implica un enfoque más claro al momento de la reparación tanto desde el punto de vista económico como de verdad y justicia. Esto especialmente porque la familia es una realidad frente al contexto social, porque atendiendo que el hombre no es un ser individual (Marcuse, 1993), sino por el contrario un ser social (Kant, 1983); (Savater, 1982); (Giddens, 1994) y por tanto los elementos de su caracterización implican no su individualización sino su colectivización, ya que el hombre solo se individualiza en tanto tiene al otro como parte de su autoconocimiento (Lazzarato, 2007), es en esta medida que se hace necesario repararlo.

La familia es por tanto el eje del ser humano, desde lo biológico, porque es posible que se conozcan sus progenitores, pero en todo caso estos existieron para que pueda existir otro. Desde el punto de vista psicoactivo el ser humano siempre está función del otro que existe tomara la decisión de amar u odiar según el contexto que habita, pero para ello requiere de la existencia y proximidad de ese otro. Por tanto, el ser humano no es víctima en su individualidad, sino en función del otro que te afecta. Razón por la cual el individuo no es víctima individual, siempre existirá la familia cercana o lejana afectada por ese dolor, ante la ausencia de esa víctima, ante el dolor que me expresa, por la omisión o acción dentro del grupo familiar. 
Es por ello que la mesa de conversación comprende dicha situación, y los incluye dentro de los presupuestos y premisas de reparación al expresar lo siguiente:

El impacto del conflicto sobre quienes participaron directamente en él como combatientes y sobre sus familias y entornos. (Mesa de conversaciones de la Habana, 2015, p. 12)

Unidad para la Búsqueda de Personas dadas por Desaparecidas en el contexto y en razón del conflicto En todo caso la UBPD entregará a los familiares un reporte oficial de la información que haya logrado obtener sobre lo acaecido a la persona o las personas dadas por desaparecidas. (Mesa de conversaciones de la Habana, 2015, p. 17)

Promover la coordinación interinstitucional para la orientación de, y la atención psicosocial a, los familiares de las personas dadas por desaparecidas en el contexto y en razón del conflicto armado (Mesa de conversaciones de la Habana, 2015, p. 18)

Cuando sea posible, garantizar la entrega digna a los familiares de los restos de las personas dadas por desaparecidas en el contexto y en razón del conflicto armado, siempre atendiendo las diferentes tradiciones étnicas y culturales (Mesa de conversaciones de la Habana, 2015, p. 19).

Garantizar la participación de los familiares de las personas dadas por desaparecidas en el contexto y en razón del conflicto armado, en los procesos de búsqueda, identificación, localización y entrega digna de restos. (Mesa de conversaciones de la Habana, 2015, p. 19)

Entregar a los familiares un reporte oficial detallado de la información que haya logrado obtener sobre lo acaecido a la persona dada por desaparecida, al término de la ejecución del plan de búsqueda correspondiente. Los restos no identificados o no reclamados por sus familiares deberán ser preservados y estarán a disposición de las autoridades competentes para la satisfacción de los derechos de las víctimas. (Mesa de conversaciones de la Habana, 2015, p.19)

Todas estas premisas y postulados indican claramente el nivel de importancia que representa para el proceso de paz la familia como estandarte de la reparación y protección y como estas deben ser discutidas no solo al interior del proceso, sino dentro de los respectivos debates del congreso (Durango Álvarez, Valencia Grajales, \& Marín Galeano, 2013). Sin embargo, dichas aseveraciones requieren de morigerar los términos, porque los mismos en Colombia no parecen incluir a los miembros LGBTI en caso de familias monoparentales, o a los familiares indirectos, nacidos de la amistad prolongada como ocurre con personas que no tiene vínculos familiares sanguíneos directos, o los compañeros permanentes no declarados judicial o civilmente. Lo que evidencia una posible inequidad a futuro. 


\section{Conclusiones.}

No es posible afirmar hoy que la familia pueda ser considerada una víctima autónoma, a pesar que sobre ella se esté dando los primeros pasos en ese sentido, sin embargo, dicha afirmación debe ser revaluada, ya que el ser humano se desarrolló en familia, sea de sangre (ius sanguineus) o construida artificialmente (civil, afectiva, social) lo que en el fondo construyo la sociedad romana, y edifica las sociedades cristianas y aun hoy determinan las sociedades modernas.

Ahora bien, la familia si es un actor valido al momento de hablar de conversaciones de paz, porque la misma es una víctima colectiva directa de una afectación individual de uno de sus miembros, como lo es la afectación misma de la sociedad cuando los hechos victimizantes se tornan en generalizados.

Es por ello que la afectación y los hechos producto de la producción de daño sobre uno de sus miembros termina por generar múltiples efectos que se pueden evidenciar en el siguiente grafico

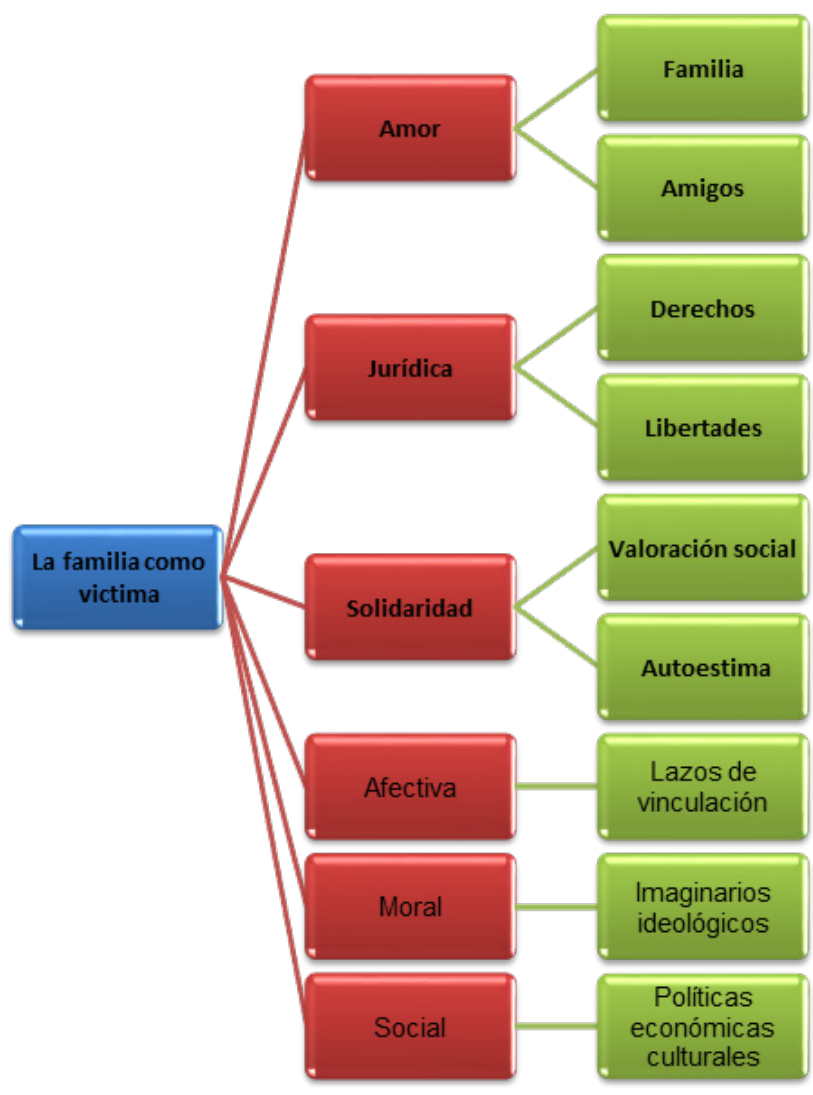

Gráfico: construcción propia del autor 
En él se aprecia los elementos que deben ser tenidos en cuenta al momento de realizar una negociación de paz, e implementar la justicia transicional ya que la familia puede tener diferentes niveles de afectación como lo son principalmente la pérdida del otro o de los sentimientos por el miembro de dicho grupo, jurídicos porque se violan los derechos humanos y la única forma de protegerlos es no afectándolos, razón por la que no repetición es un elemento necesario al momento de ser reparados, económicos, en los casos en que se da una pérdida total del miembro de la familia, y la perdida de elementos de la solidaridad que se reflejan en la perdida de valoración social y la autoestima que se puede presentar en todos o algunos miembros de la familia, ante la pérdida o la solidaridad presentada ante el dolor o afectación de la víctima miembro de la familia.

Finalmente, el mundo de lo posible esta potenciado en la medida en que nos permitimos soñar uno nuevo con las herramientas del presente, es decir, debemos buscar un punto medio entre lo existente y lo que visionamos para alcanzar una mayor conciencia como diría Zemelman: "el mundo de las necesidades, sin caer en el particularismo de ninguna demanda concreta. Mundo constituido por dos génesis de necesidades: la memoria (tradición, inercia), y, de otra parte, las visiones de futuro, la utopía de algo. El punto de tensión entre estas dos grandes polaridades delimita el primer ámbito de las posibles necesidades". (Zemelman, 2010, p. 3) 


\section{Referencias bibliográficas.}

Auto que resuelve recurso de apelación, frente al incidente de solicitud de cancelación de títulos fraudulentos y restitución de bienes., 44688 (Corte Suprema de Justicia, Sala De Casación Penal. 11 de febrero de 2015).

Álvarez, S. D. (2006). Manual de Derecho de Familia. Medellín: Universidad de Medellín.

Asamblea General de las Naciones Unidas. (1989). Convención Internacional sobre los Derechos del Niño. Nueva York: Naciones Unidas.

Bel Bravo, M. A. (2000). La familia en la historia Propuestas para su estudio desde la "nueva" historia cultural. Madrid: Ediciones Encuentro, S.A.

Bentham, J. (2000). Principles of morals and legislation. Canadá: Canada Macmaster Universuty. Obtenido de http://socserv2.socsci.mcmaster.ca/econ/ugcm/3113/ bentham/morals.pdf

Bentham, J. (2005). Defence of Usury. London: Payne and Foss. Obtenido de http://www. econlib.org/library/Bentham/bnthUs.html

Bergquist, C. W. (1981). Café y conflicto en Colombia, 1886-1910: La guerra de los mil días: sus antecedentes y consecuencias. (M. Melo, Trad.) Medellin: Biblioteca colombiana de ciencias sociales FAES.

Campo Chicangana, A. R. (2003). Montoneras, deserciones e insubordinaciones yanaconas y paeces en la guerra de los mil dias. Cali: Feriva.

Castoriadis, C. (2007). Democracia y relativismo debate con el MAUSS. Madrid: Editorial Trotta.

César, J. (1986). La guerra de las Galias con las notas de napoleón. Ediciones Orbis, S. A.

CICR (Comité Internacional de la Cruz Roja). (2005). Derecho Internacional Humanitario. Respuestas a sus preguntas. Ginebra: CICR. Obtenido de https://www.icrc.org/ spa/assets/files/other/icrc_003_0703.pdf

CICR (Comité Internacional de la Cruz Roja). (2008). ¿Cuál es la definición de conflicto armado según el Derecho Internacional Humanitario? Ginegra: CICR. Obtenido de https://www.icrc.org/spa/assets/files/other/opinion-paper-armed-conflict-es.pdf

Clausewitz, K. ( 1984). De la guerra. Barcelona: Editorial Labor.

Debray , R. (1997). Transmitir. Argentina: Manantial.

Debray, R. (1998). Vida y muerte de la imagen: historia de la mirada en occidente. España: Paidós.

Debray, R. (2008). Transmitir más, comunicar menos. revista Lectiva Medellín(16), 147160. 
Durango Álvarez, G. A., Valencia Grajales, J., \& Marín Galeano, M. S. (2013). La participación politica como derecho fundamental: análisis desde la democracia deliberativa. Medellín: Centro de Publicaciones de la Universidad Nacional de Colombia.

El Tiempo. (13 de mayo de 2008). 140 bienes de los paramilitares en manos de familiares o testaferros serán ocupados por la Dijin. Obtenido de www.eltiempo.com: http:// www.eltiempo.com/archivo/documento/CMS-4163727

Engels, F. (2006). El origen de la familia, la propiedad privada y el estado. Madrid: Fundación Federico Engels.

Fernández, G. (2005). La agonía del Imperio Romano de Occidente. Revista de Historia Antigua, 23(1), 325-328.

Foucault, M. (1986). El nacimiento de la clínica; una arqueología de la mirada médica. (F. Perujo, Trad.) México: Siglo XXI Editores.

Foucault, M. (1999). Vigilar y castigar; Nacimiento de la prisión. (A. Garzón del Camino, Trad.) Medellin: Siglo XXI.

Foucault, M. (1980). El ojo del poder. (J. Varela, \& F. Álvarez Uria, Trads.) Barcelona: La Piqueta.

Foucault, M. (1998). Un diálogo sobre el poder y otras conversaciones; Los intelectuales y el poder. (E. Lynch, Trad.) Madrid: Gedisa.

Foucault, M. (1998). Verdad y las formas jurídicas. (E. Lynch, Trad.) Madrid: Gedisa.

Freire, P., \& Faundez, A. (2014). Por una pedagogía de la pregunta critica a una educación basada en respuestas a preguntas inexistentes. España: Siglo Veintiuno Editores.

Freud, S. (1980). Tótem y Tabú. En S. Freud, Obras completas (Vol. XIII). Argentina: Amorrortu.

Freud, S. (1997). Obras Completas de Sigmund Freud (Vol. I). Madrid: Biblioteca Nueva.

Freud, S. (2006). El malestar en la cultura. Madrid: Alianza Editorial.

Gaii. (1845). Institvtionvn Cummentarivs IV In codice rescripto bibliothecae capitularis veronensis nuper repertarum. Madrid: Sociedad literaria y tipográfica.

García Durán, M., Sarmiento Santander, F., \& Caraballo Acuña, V. (2009). Tendencias de la paz en Colombia. Bogotá: Cinep. Obtenido de https://issuu.com/cinepppp/ docs/tendencias_de_la_paz_en_colombia_cap_tulo_1_compil

Gayo. (1965). Instituciones jurídicas. (J. Núñez de Prado, Trad.) España: Editorial Iberia.

Geertz, C., \& Geertz , H. (1975). Kinship in Bali. Chicago: Chicago University Press.

Giddens, A. (1994). El capitalismo y la moderna teoría social. Barcelona: Labor. 
Hernández , S. R., Fernández, C. C., \& Baptista , L. P. (2010). Metodología de la investigación. Bogotá: McGraw Hill.

Herrera, C. G. (2006). El panóptico moderno. Revista de Filosofia A Parte Rei(46).

Jiménez, M. D. (2009). Responsabilidad penal juvenil en Colombia: de la ideología tutelar a la protección integral. Revista Electrónica de la Facultad de Derecho y Ciencias Politicas de la Universidad de Antioquia, 1-7.

Kant, I. (1983). Fundamentación de la metafisica de las costumbres. Buenos Aires: Editorial Porrúa.

Keegan , J. (2014). Historia de la guerra. Madrid: Turner.

Kristeva , J. (1998). El porvenir de una revuelta. España: Seix Barral.

Kuhn, T. S. (2004). La estructura de las revoluciones cientificas. México: Fondo de Cultura Económica.

Kuper, A. (1988). The invention of Primitive Society. Transformations of an Illusion. London and New York: Routledge.

Lazzarato, M. (2007). El acontecimiento y la política la filosofia de la diferencia y las ciencias sociales. En M. Zuleta, H. Cubides, \& M. R. Escobar, ¿Uno o varios mundos? Diferencia, subjetividad y conocimientos en las ciencias sociales contemporáneas (págs. 23-36). Bogotá: Siglo del hombre editord.

Leal Buitrago, F. (2002). Conflicto y política en Colombia. Revista Foro(46), 87-92.

Malhotra, N. K. (2008). Investigación de Mercados. Un Enfoque Práctico. México: Pearson Prentice-Hall.

Marcuse , H. (1993). El hombre unidimensional ensayo sobre la ideología de la sociedad industrial avanzada. México: Planeta de Agostini.

Marquard, O. (2001). Marquard, Odo. (2001). Narrare necesse est. En Filosofía de la compensación. Escritos sobre antropología filosófica. Barcelona: Paidós.

Maturana Romesin , H. (2005). Emociones y lenguaje en educación y politica. Santiago: JC Saez Editor.

Mèlich, J.-C. (2006). El trabajo de la memoria o el testimonio como categoría didáctica. Revista Debates Enseñanza de las Ciencias Sociales, 115-124.

Merton, R. K. (2003). Teoría y estructura sociales. España: Fondo de Cultura Económica.

Mesa de conversaciones de la Habana. (2012). Acuerdo general para la terminación del conflicto y la construcción estable y duradera. Habana: República de Colombia FARC-EP. Obtenido de https://www.mesadeconversaciones.com.co/sites/default/ files/AcuerdoGeneralTerminacionConflicto.pdf 
Mesa de conversaciones de la Habana. (2015). Punto 5. Acuerdo sobre las víctimas del conflicto: Borrador conjunto. Habana: República de Colombia-FARC-EP. Obtenido de https://www.mesadeconversaciones.com.co/sites/default/files/borradorconjunto-acuerdo-sobre-las-victimas-del-conflicto-1450190262.pdf

Morgan, L. (1870). Systems of consanguinity and affinity of the human family. Washington: The Smithsonian Institution.

Musitu, G., Buelga, S., Lila, M., \& Cava, M. (2001). Familia y adolescencia: Un modelo de análisis e intervención psicosocial. Madrid: Sintesis .

Needham, R. (1971). Remarks on the Analy\& of Kinship and Marriage. En R. Needham, Rethinking Kinsh and Marriage (págs. 1-34). London: Tavistock.

OHCHR (Oficina del Alto Comisionado de los Derechos Humanos de las Naciones Unidas). (2015). ¿Qué son los Derechos Humanos? New York: OHCHR. Obtenido de www. ohchr.org: http://www.ohchr.org/SP/Issues/Pages/WhatareHumanRights.aspx

Ortiz sarmiento, C. M. (1985). Estado y subversión en Colombia, la violencia en el Quindio años 50. Bogotá: Fondo editorial CEREC.

Orwell, G. (1980). 1984. España: Salvat Editores S.A.

Pécaut, D. (2008). Las FARC ¿Una guerrilla sin fin o sin fines? Bogotá: Editorial Norma.

Pécaut, D. (1987). Orden y violencia: Colombia 1930-1953 (Vol. II). Medellín: Siglo XXI.

Revista Semana. (16 de 06 de 2016). A la deriva un millón de hectáreas para campesinos sin tierra. Obtenido de www.semana.com: http://www.semana.com/nacion/articulo/ corte-constitucional-ordena-revisar-politicas-para-recuperar-baldios / 477953

Sáiz Serrano, J. (2003). Guerra y nobleza en la corona de Aragón. La caballeria en los ejércitos del rey (siglos XIV - XV). Valencia: Departamento de Historia Medieval - Universitat de Valencia. Obtenido de http://www.tesisenred.net/bitstream/ handle $/ 10803 / 9994 /$ saiz.pdf?sequence $=1$

San Agustín. (2007). La ciudad de dios. (A. Alea, Trad.) España: Tecnos.

Savater , F. (1982). Ética ciudadana. Bogotá: Editorial Ariel.

Sibilia, P. (2008). La intimidad como espectáculo. Buenos Aires: Fondo de Cultura Económica.

Tejeiro, L. E. (2005). Teoría general de niñez y adolescencia. Bogotá: Universidad de Los Andes.

Trautmann, T. R. (1987). Lewis Henry Morgan and rhe Invention of Kinship. Berkley: University of California Press.

Tucidides. (1996). Historia de la Guerra del Pelopoleso. Barcelona: Ediciones Orbis, S.A. 
UNICEF. (2003). Nuevas formas de familia. Perspectivas nacionales e internacionales. Uruguay: UNICEF - UDELAR.

Universidad Rafael Landivar. (1995). Acuerdos de paz firmados por el gobierno de la República de Guatemala y la Unidad Revolucionaria Nacional Guatemalteca (URNG). Obtenido de www.gt.undp.org: http://www.gt.undp.org/content/dam/guatemala/ docs/publications/undp_gt_Acuerdos-de-Paz-O.pdf

Uribe de Hincapié, M. T. (2007). Desplazamiento forzado en Antioquia. Aproximaciones teóricas y metodológicas al desplazamiento forzado en Colombia. Bogotá: Kimpres.

Valencia Grajales, J. (2009). Desplazamiento forzado en Colombia; del interior hacia fuera de las fronteras. Kavilando, 1(2), 14-26.

Valencia Grajales, J. F. (2010). Las acciones afirmativas: conceptualización y caracterización desde la Corte Constitucional. En Politica y Derechos Fundamentales: Jornadas Académicas. Colombia: Facultad De Ciencias Humanas Universidad Nacional De Colombia.

Valencia Grajales, J. F. (2011). Evolución de las Estrategias de Guerra. El Ágora USB, 11(1), 67-88.

Valencia Grajales, J. F. (2011a). Las FARC un camino entre las nuevas guerras. Kavilando, $3(2), 42-47$.

Valencia Grajales, J. F. (2014). Gustavo Rojas Pinilla: Dictadura o presidencia: La hegemonía conservadora en contravía de la lucha popular. El Ágora USB, 14(2), 537-550.

Valencia Grajales, J. F., \& Insuasty Rodríguez, A. (2009). ¿ंel terror y el abuso como política pública? estudio de caso, Juan José Chaux . Kavilando, 1(2), 34 - 39.

Valencia Grajales, J. F., \& Insuasty Rodríguez, A. (2012). Legalización e inclusión social: barrio 20 de Julio del municipio de Urrao. Colombia. El Ágora USB, 12(2), 437 - 469.

Valencia Grajales, J. F., \& Marin Galeano, M. S. (2008). Derechos fundamentales violados por el desplazamiento forzado y su posterior violación al momento de atención. $E l$ Ágora USB, 8(1), 161-195.

Valencia Grajales, J. F., \& Marín Galeano, M. S. (2010). La formación histórica de los partidos políticos en Colombia con motivo del bicentenario. Kavilando, 2(1), 8-21.

Villa Gomes, J. D., \& Insuasty Rodriguez, A. (2016). Significados en torno a la indemnización y la restitución en víctimas del conflicto armado en el municipio de San Carlos. El Ágora USB, 16(1), 165-191. Obtenido de http://revistas.usb.edu.co/index.php/ Agora/article/view/2171/1899

Walford, E. (1846). The Ecclesiastical History of Evagrius: A History of the Church from AD 431 to $A D$ 594. Evolution Publishing. 
Zamiatin, Y. (2005). Nosotros. (M. Estapé, Trad.) Zaragoza: Prames S.A.

Zemelman, H. (1992). Los horizontes de la razón II: Historia y necesidad de utopia. Barcelona: Anthropos/ El Colegio de México.

Zemelman, H. (1994). Memoria y utopía. El sujeto como constructor de realidades y racionalidad y ciencias sociales. Barcelona: Anthropos.

Zemelman, H. (1996). Problemas utópicos y antropológicos del conocimiento. México: El Colegio de México.

Zemelman, H. (1998). El conocimiento como desafio posible. Argentina: EDUCO.

Zemelman, H. (2005). Voluntad de conocer. El sujeto y su pensamiento en el paradigma crítico. México: Anthropos Editorial; Centro de Investigaciones Humanísticas Universidad Autónoma de Chiapas.

Zemelman, H. (2010). Sujeto y subjetividad: La problemática de las alternativas como construcción posible. Polis, 9(27), 1-10. Obtenido de https://polis.revues.org/943

Nota:

i El presente artículo es producto de la línea de investigación en familia y el proyecto de investigación La familia en el marco de la justicia transicional: retos y reconocimientos adscrito to a la FUNLAM y el apoyo de KAVILANDO 